considerable discussion. It was recognized that the main burden for this falls on governments, particularly in developing countries where the situation is made more difficult because there is little or no industry to provide additional funds. It was suggested that countries providing assistance for developing countries should be prepared to allocate a larger proportion of their aid funds for scientific research. It is essential, however, that a proper balance should be maintained between the provision of training opportunities in the shape of fellowships, etc., and the provision of equipment and facilities. Training is useless if the trainees do not have equipment and facilities available on their return to their home countries; on the other hand, it is useless to provide expensive and complicated equipment if skilled staff is not available to use it properly.

The encouragement of scientific research in developing countries through regional collaboration in such activities as conferences, symposia and training courses was a major topic of discussion. This led naturally to a discussion of the programme of the Unesco South-East Asia Science Co-operation Office, which is already fulfilling such an important role in the region. In relation to the needs, however, its resources are much too limited, and the meeting agreed that Unesco should be asked to make a greatly increased budgetary provision for its work in the area. The meeting agreed that the following activities, which are all urgently needed in the region, could appropriately be undertaken by Unesco: the provision of information on research programmes being undertaken in the region and on facilities for training and technical assistance; the encouragement of symposia on scientific subjects of special interest to
South-East Asia; the provision of training courses for technicians, and refresher courses for science teachers; the encouragement of more visits to the region by scientists. The meeting suggested that the Unesco South-East Asia Science Co-operation Office should consider the possibility of arranging a meeting of librarians and documentation experts of the area. and it recommended that the present and proposed programmes of the Office in the fields of science teacher training, marine science research and humic tropics research should be confirmed and strengthened.

The whole conference demonstrated clearly how effective international meetings on a limited scale can be in promoting understanding and friendship. I believe that the meeting will have valuable practical results in increasing active collaboration between countries of the region in seientific matters. Many of them have scientific problems in common, and it was clear from the discussions at Bandung that they face many similar organizational and administrative problems in building up and strengthening their scientific organizations. The Unesco South-East Asia Science Co-operation Office is to be congratulated in taking the initiative in arranging the meeting, and it is obvious from the discussions that it can play a much greater part in the scientific life of the region if it can be provided with greater support. Such increased activity would be welcomed by all countries represented at the meeting.

All the delegates to the meeting would agree that it was a most successful one, and they have carried away with them the happiest memories of the gracious hospitality of their Indonesian colleagues, and the exquisite beauty of the Java countryside.

GUY B. GRESFORD

\title{
RECENT ADVANCES IN COCONUT RESEARCH IN INDIA
}

$\mathrm{T}$ HE Agricultural College, Vellayani, Trivandrum, was the venue of the first conference of the coconut research workers in India organized by the Indian Central Coconut Committee, Ernakulam. India is the second largest producer of coconuts, a commodity occupying an important place in international commerce. With the advent of the Indian Central Coconut Committee in 1945 and with the establishment of two Central Coconut Research Stations and seven Regional Research Stations in the different coconut-growing States of the country, coconut researeh has in recent years gained considerable impetus and it was therefore quite opportune that research workers engaged from all over India should meet and discuss recent advances achieved in their field of work. The Conference was held during December 21-23, 1959, and was attended by more than seventy research workers, representatives of the Kerala Department of Agriculture and the Agricultural College, and some prominent coconut growers. Prof. L. S. S. Kumar, principal of the Agricultural College, presided. Some forty-five papers were presented and discussed at the conference.

Eleven papers covered the subjects falling under the purview of agronomy and general plant nutrition. In the first paper, by Mr. M. M. Krishna Marar and Dr. K. M. Pandalai (Kasaragod), the results of observations made in some long-term (40-year) experi- mental plots on the coconut were presented. The more important of the conclusions drawn were that (1) regular inter-cultivation and manuring are necessary to step up and maintain the yield at high level, and (2) regular inter-cultivation by itself is highly effective in increasing the yields even in the absence of manuring.

The same authors discussed in another paper the beneficial effects of nitrogen, phosphorus and potassium manuring on inducing flowering and bearing in adult non-bearing palms. Messrs. C. M. John and K. Jacob (Bangalore) reviewed the results of the extensive fertilizer demonstration scheme on coconuts carried out in growers' holdings on the west coast of India and established that manuring with the standard dose of $0.75 \mathrm{lb}$. nitrogen, $0.75 \mathrm{lb}$. phosphate and $1.5 \mathrm{lb}$. potassium together with 50-100 $\mathrm{lb}$. green leaves per tree per year resulted in an increase of 35 per cent in terms of nuts, or 44 per cent in terms of copra, providing a net profit of Rs. 88.00 per acre. Miss K. Vijayalakshmi (Kasaragod) dealt with the various factors regarding moisture in soils of coconut plantations and outlined the various steps to be taken to conserve it. Messrs. T. Kailas Rao and T. Srirama Rao (Ambajipet) showed that for the alluvial soils of the coconut areas of Andhra Pradesh, sunnhemp is the most suitable green manure crop. The practices that have to be tackled when 
introducing coconut cultivation on a large scale in new regions such as Assam were discussed by $\mathrm{Mr}$. P. R. Nath (Kahikuchi).

Certain aspects of the nutrition of the coconut palm were discussed by Dr. K. M. Pandalai and coworkers (Kasaragod). Dr. Pandalai showed that in the disorders or abnormal conditions such as foliar vellowing, chlorotic condition of the seedlings, petiole breaking, barren nut production, etc., met with in the coconut palm, there is a characteristic accumulation of nitrogen, phosphorus and potassium, etc., as compared with healthy tissues, suggesting some disturbance of optimum nutrient ratios, consequent inadequate metabolism and/or impaired translocation. Mrs. C. K. Thankam (Kasaragod) provided relevant data to justify the above general biochemical pattern of nutrient maladjustment in respect of barren nuts. Mr. P. L. Ramanandan (Kasaragod) dealing with the foliar yellowing condition of the palms, showed that it could be ameliorated to some extent by balanced nitrogen, phosphorus and potassium manuring supplemented with micronutrients such as molybdenum, copper and boron. Mr. C. K. Balakrishnan Nambiar (Kasaragod) showed that, in coconut seedlings, growth as well as leaf composition was correlated to a large extent with the composition of the growth medium, and that unbalanced nitrogen, phosphorus and potassium supply decreased growth and vigour and produced characteristic deficiency symptoms. Mr. N. G. Pillai (Kasaragod) traced the changes in the mineral composition of the different parts of the nuts, such as husk, shell, kernel and nut water, in the course of development from the button stage to ripe nut.

Five papers dealt with subjects of botanical interest. Messrs. S. R. Gangolly, T. P. Gopalakrishnan and co-workers (Kasaragod) presented data to show that synthetic growth-promoting substances such as $\beta$-indole propionic acid, $\beta$-indole butyric acid in suitable concentrations can be used instead of coconut water along with 2,4-dichlorophenoxy acetic acid for arresting button shedding in the coconut and promoting satisfactory growth of nuts. In another paper Messrs. S. R. Gangolly, M. C. Nambiar, Rama Varma and K. M. Pandalai discussed the distribution of coconut pollen in the atmosphere in relation to weather factors such as humidity, maximum and minimum temperature, sunshine, etc. Mr. R. Gopinathan Nair (Kasaragod), in tracing the anatomical development of the coconut fibre, showed that the fibre strands begin to differentiate in the ovary wall of the female flowers four to five months prior to the opening of the spathes, and that they grow for the main part into typical fibrovascular bundles having a few xylem and phloem elements surrounded by a sheath of fibrous cells. Messrs. R. V. Pillai and K. Satyabalan (Kasaragod) in their paper described the seasonal variations in the yield and nut characteristics of thirteen exotic cultivars of the coconut, and showed the existence of inherent variations among them. Mr. Josy Joseph (Kasaragod) in his paper showed that $F_{2}$ progeny seedlings of $T \times D$ (open pollinated or control pollinated) were better than $\bar{F}_{1}$ in vigour as judged by vegetative characters relating to growth.

As many as thirteen papers dealt with the different aspects of the investigations on the diseases of the coconut palm. Mr. U. K. Nair and Dr. K. Radha (Kayangulam) presented data to show that manuring and spraying were generally effective in reducing the adverse effects of the leaf disease. Miss T. O. Prasan- nakumari, Dr. K. Radha and Mr. V. C. Kurian (Kayangulam) dealing with the efficiency of different copper fungicides for the control of leaf disease concluded that Bordeaux mixture, Kirti copper and 'Fungimar' were more effective than the others triod.

Dr. P. Shanta, Dr. K. P. V. Menon and co-workers (Kayangulam) presented four papers dealing with their investigations on the virological aspects of the wilt disease of the coconut palm. In the first paper. they presented results that tend to support the virus hypothesis of the wilt disease. In their second paper they described the host-range of the virus, and showed that the virus can be experimentally trans. mitted to cowpea seedlings by sap inoculation. In another paper Dr. P. Shanta, Dr. K. P. V. Menon and Mr. K. J. Thommen (Kayangulam) adduced evidence to show that chlorosis and flaccidity of the leaves in the diseased coconut palms are only secondary symptoms brought about by the formation and accumulation of toxic materials in the leaves. Dr. K. Radha and Mr. T. S. S. Rawther (Kayangulam) reported negative correlation between the rhizosphere fungi and rainfall conditions in their studies on the influence of seasonal factors on the rhizosphere microflora with reference to the wilt disease in the coconut palm.

A series of seven papers on the chemical studies on the leaf and wilt disease of the coconut were presented by Messrs. E. J. Verghese, M. P. Sankaranarayanan, S. Robert Cecil, M. K. C. Nair and A. S. Mathew (Kayangulam). In the first two papers they reiterated the salient features of observations made on the incidence of the root and leaf diseases of the palms, and provided data which confirmed the earlier findings regarding the accumulation of major nutritient factors in the diseased tissues. Different aspects relating to the changes in the concentration under water-logged conditions, partieularly of possible toxic agents such as ferrous iron, aluminium, organic acids, etc., which could injure plant tissue, were discussed in the third paper. The results of soil survey of healthy and diseased coconut gardens to throw light on the influence of soil conditions in relation to the disease formed the subject of another paper. The ineffectiveness of lime, ash and Chilean nitrate to improve the condition of diseased trees was reported in two other papers by Messrs. M. R. Chettiar, E. J. Verghese, P. C. John, P. V. Channey and M. P. Sankaranarayanan. In the last paper of the series it was concluded that cadmium toxicity is not a factor associated with the disease condition of the coconut palm.

Six papers presented results of investigation on the pests of the coconut palm. Messrs. K. R. Mohan Rao and C. Seshagiri Rao (Ambajipet) described the different pests of the palm prevalent in the Andhra Pradesh, and gave an account of the biological method of control adopted by them against Nephantis serinopa. Mr. G. B. Pillai and Dr. C. Kurian (Kayangulam) in their work on the insecticidal efficiency of dieldrin concluded that 0.05 per cent is the optimum minimum concentration for use against Nephantis serinopa. Reporting the results of several insecticidal trials against Rhynchophorus ferrugineus F., Mr. K. Mathen and Dr. C. Kurian (Kayangulam) held the view that both larvæ and adults suffered 92 per cent mortality of grubs at 0.5 per cent and 100 per cent mortality of adults at 0.1 per cent, seven days after treatment, endrine giving best results. 
The results of observation on the incidence of the rhinoceros beetle and the extent of damage done by it under field conditions were presented by $\mathrm{Mr}$. C. P. Ramachandran and Dr. C. Kurian (Kayangulam). Detailed studies of Perisierola nephantidis, an ectophagous larval parasite of Nephantis serinopa, were reported by Mr. J. Antony and Dr. C. Kurian. Mr. K. V. Joseph (Vellayani), based on the work done by him, emphasized the need to exercise caution in the matter of using DDT for large-scale spraying in coconut areas because of the risk involves in adversely affecting the population of parasited and predators that normally help to keep pests under control in Nature.

Other papers were presented and discussed, and some were submitted only. All the papers submitted for the Conference are being printed as a special volume of the Indian Coconut Journal (published by the Indian Central Coconut Committee, Ernakulam, South India).
K. M. Pandalai

\section{MEDICAL RESEARCH IN THE BRITISH CARIBBEAN}

T HE fifth annual scientific conference organized by the Standing Advisory Committee for Medical Research in the British Caribbean was held at the University College of the West Indies, Jamaica, during April 2-4. The topic for the meeting was the application of the laboratory to problems of clinical medicine. Doctors from the Caribbean islands, British Guiana, British Honduras, the Bahamas, Great Britain and the United States attended. Thirty-five papers were read and discussed. Prof. A. C. Frazer (University of Birmingham) took the chair on the first day.

The first session was devoted to cardiovascular disorders. A number of hospital studies and field surveys were reported from Jamaica, Trinidad, British Guiana and St. Kitts, by Drs. J. A. Tulloch, G. Wattley, H. Hamilton and K. Stuart. Hypertensive heart disease was the most common cardiac cause for hospital admission followed by luetic and then rheumatic heart disease. Acute rheumatic fever was common, and in Trinidad affected the East Indian to a greater extent than the Negro. Cor pulmonale was uncommon in both Trinidad and Jamaica, but was seen with greater frequency in British Guiana. In British Guiana and Trinidad it occurred almost exclusively in the East Indian. No satisfactory explanation of this racial difference was forthcoming. Myocardial infarction was uncommon in all the territories. This was of interest as aortic atheroma is as common in Jamaica as in the United States of America, although coronary artery atheroma is less severe in Jamaica than in the United States. The association of aortic and coronary atheroma with essential hypertension, diabetes, age and sex was discussed by Dr. W. B. Robertson. The importance of heart disease in the general population was illus. trated by the report from Barbados of a chest X-ray survey of 3,000 subjects. This showed a $10 \cdot 7$ per cent incidence of cardiovascular abnormality, and a considerable proportion of these had a positive serological test for syphilis. Yaws has not been recognized in Barbados for many years. This stressed the fact that symptomless cardiovascular syphilis may be more common than has been thought and therefore poses an important public health problem. In the discussion of this paper the urgent need for a test, serological or otherwise, that will differentiate syphilis from yaws was stressed.

Hypertension is common and field surveys carried out in Jamaica and St. Kitts were reported by Dr. K. L. Stuart. The levels of blood pressure in St. Kitts were slightly higher than those reported by the Medical Research Council team in South Wales, whereas in Jamaica the figures were comparable to those from South Wales. An investigation into the occurrence of significant bacilluria in the general population was also reported by Dr. Stuart. There was a considerably higher incidence of bacilluria in the hypertensive female, and this increased with parity. The relationship of bacilluria to hypertension was discussed, and the possibility that pyelonephritis was responsible for the greater incidence of hypertension in the elderly female was suggested. A postmortem study of hypertensive cases reported by Drs. Ling and Stuart did show that renal hypertension was responsible for 50 per cent of the cases, and that chronic pyelonephritis accounted for one-third of the renal cases.

Diabetes mellitus was discussed at the second session. It was pointed out by Dr. J. A. Tulloch that the prevalence of diabetes in Jamaica was a little more than 1 per cent of the adult population, and that only about 40 per cent of the cases were already known to have diabetes. The retiology was reviewed and was considered to be very similar to that reported from temperate countries. A consideration of the $J$ type cases was reported by Drs. D. MacIntosh and $J$. Tulloch, which indicated that this was not a distinct type, but was a phase in the natural history of the badly treated type II patient. The results of treatment with chlorpropamide were reported from Trinidad by Dr. T. Poon-King. A considerable proportion of his cases responded satisfactorily. The distribution of blood groups in diabetic subjects was also reported from Trinidad. In both male and female cases there was a low incidence in group $\mathrm{O}$. Males showed an excessive group $\mathrm{B}$ and females an excess of group A over that occurring in the local population. A study of liver enzymes in human diabetes was reported by Dr. S. J. Patrick. This largely confirmed animal experiments.

On the second day Prof. E. T. C. Spooner (London School of Hygiene and Tropical Medicine) took the chair. Dr. R. D. Montgomery of the Medical Research Council Tropical Metabolism Unit reported that the oxygen uptake per unit of body weight was not reduced even in severe malnutrition. During recovery the increase became much greater and evidence was given that this was related to thyroid activity. Drs. J. C. Waterlow and D. I. M. Picou reported preliminary observations from isotope studies that, in protein malnutrition, the economy of protein is achieved not by a decreased rate of katabolism but by an increased degree of re-utilization. Although the extent of protein synthesis may be reduced through shortage of supplies, the capacity for synthesis seemed in most cases to be unimpaired. The occurrence of magnesium deficiency in malnutrition was reported 